\title{
A BIBLIOMETRIC ANALYSIS ON JOB STRESS USING VISUALIZING NETWORK
}

\author{
Amanpreet Kaur Sidhu \\ Research Scholar, Management Department \\ I.K.Gujral Punjab Technical University, Kapurthala, India. \\ Harwinder Singh \\ Professor, Department of Mechanical Engineering, \\ Guru Nanak Dev Engineering College, Ludhiana, India. \\ Sandeep Singh Virdi \\ Assistant Professor, School of Management Studies, \\ Punjabi University, Patiala, India \\ Raman Kumar \\ Associate Professor \\ Mechanical Engineering Department, \\ Chandigarh University, India
}

\begin{abstract}
Job stress is the most prevalent issue of the current scenario. It is observed that one out of four employees is affected by stress; thereby, it has attained the interests of many researchers. The rapid evolution of job stress research papers in the last years resulted that there is a need to conduct a detailed analysis of literature in this field. To address this problem, some researchers published a few review papers on job stress from different perspectives. Nonetheless, papers have not been published on job stress with bibliometric analysis. In the present study, an attempt is made to investigate the job stress publications with bibliometric analysis. Scopus database is considered as a literature database. Through analysis, article, conference paper, book chapter, review, Letter, editorial, note, book, short survey, data paper, Erratum, Retracted, and Undefined retrieved from Scopus indexes from 2010 to 2020. The collected data is analyzed against six research questions. The results revealed valuable insight, including annual publications, top contributing authors, Journal \& affiliation, type of publication, subject area, the top country in publication, and keyword network. It is found from the analysis that the interest of researchers in job stress was at a peak in 2016. The top research area associated with job stress includes medicine, Social Sciences, and Business Management \& accounting. Lambert, E.G. contributed the most in job stress publications. These findings can guide future researchers to set up a baseline before instigating a job stress research work.
\end{abstract}

Keywords: Job Stress, Bibliometric, Keywords Network

\section{INTRODUCTION}

In recent research, job stress has been identified as a 'psychosocial' threat. Stress has always been an important part of an individual's lifestyle. Its roots can be traced back to the Latin word "stringere" in the literary works of the 17th century, which means narrowing; this concept is also known as difficulty, struggle, adversity, or affliction.(Sidhu, Singh, Virdi, \& Kumar, 2019). Selye (1936), considered the father of stress. He first introduced stress into the life sciences. Selye defined stress as "a mental and physical state resulting from the unexpected differences between demand and ability of an individual to meet those demands." Various terms have synonymously been used with stress such as anxiety, frustration, and pressure(Shiva, Narula, \& Shahi, 2020). Stress is considered as the "wear and tear" of the individual's experience as they have to adjust to the changing environment (Arevalo \& Balodi, 2019). Stress has both a physical and mental effect (Kundaragi, 2015). Stress is an unavoidable component of an individual's life because complexities and competitiveness are increasing in human life. Sometimes employee's interaction with their organization creates high-level stress (Miglani \& Brar, 2017). Everybody is experiencing stress, 
although it is an economic activity, organization, business, work, study, social, and family interaction (Ramanathan, 2014).

Job is a central part of our lifestyle, and creates a great deal of tension due to uncertainty and competition. (Jaswal \& Chand, 2018). Everyone devotes their best to work, but everyone neglects the tension factor, and the same has an effect on their success and lifestyle (Li, Ai et al., 2017). Usually, everyone is worried about the results of their efficiency that can affect their performance and behavior. Employers are also bearing higher than economic pressures that lead to non-standard employment arrangements, which consequences as stress in workers (Ray, Kenigsberg, \& Pana-Cryan, 2017). According to National Statistics (2018), 595,000 (44\%) employees of Great Britain were suffering from job stress in 2017-2018(National Statistics, 2018). People of every country are under a high level of job stress, which causes harmful emotional and physical responses (Yeasmin, Ara, Khan, \& Hossain, 2015). Job stress has a great impact on health(Sidhu, Singh, Virdi, \& Kumar, 2020). Stress has become an issue of great concern. According to the statistics, one out of four employees is affected by stress (Fong, 2019). Stress associated risks consequence financial losses, low performance, absenteeism, and errors at work (Seňová \& Antošová, 2014). Even women are also bearing immense pressure (Tripathi, 2015). So it is very important to understand all the aspects of stress. Bibliometric analysis is a statistical analysis of articles, research papers, books, and other publications published in various countries in multi-disciplinary fields. As the number of publications on job stress is increasing from the last decade, there is a need for a comprehensive and systematic overview of the research status of job stress. For this purpose, the present research work attempted to explore the various papers published on job stress through bibliometric analysis. In this study, the Scopus database is used to summarize the publications on job stress

The Organizations paper is as follows. Section 2 describes the methods used in the study. Section 3 presents the results of the analysis. In Section 4, a discussion on results is provided. Section 5 gives the conclusion of the study and directions for future research.

\section{METHODS}

The methodology section consists of the research objective and data set extraction.

\section{Formulation of research questions}

The main aim of this study is to examine a bibliometric analysis of job stress papers that are indexed in the Scopus database. To accomplish this objective, some research questions have been set out to answer. These questions with their significance are given in the following table 1.

Table 1.Research questions with their significance

\begin{tabular}{|c|c|}
\hline $\begin{array}{l}\text { Research } \\
\text { Questions }\end{array}$ & Significance \\
\hline $\begin{array}{l}\text { What is the } \\
\text { annual Trend } \\
\text { of job stress } \\
\text { publications? }\end{array}$ & $\begin{array}{l}\text { It would help to determine the } \\
\text { annual volume of job stress } \\
\text { publications, which can help } \\
\text { to predict the future trend } \\
\text { also. }\end{array}$ \\
\hline $\begin{array}{l}\text { Which author } \\
\text { and journal } \\
\text { contributed } \\
\text { more to job } \\
\text { stress based } \\
\text { research? }\end{array}$ & $\begin{array}{l}\text { It would help researchers to } \\
\text { find specific studies, methods, } \\
\text { and material to carry out high- } \\
\text { quality research in job stress }\end{array}$ \\
\hline $\begin{array}{l}\text { Which area and } \\
\text { document type } \\
\text { published more } \\
\text { research work } \\
\text { on job stress? }\end{array}$ & $\begin{array}{l}\text { It will help to identify the } \\
\text { research efforts on job stress in } \\
\text { different areas and types of } \\
\text { documents. It will help the } \\
\text { researcher to identify future } \\
\text { research directions. }\end{array}$ \\
\hline $\begin{array}{l}\text { What is the } \\
\text { topmost } \\
\text { publication } \\
\text { Affiliations for } \\
\text { Job stress } \\
\text { papers? }\end{array}$ & $\begin{array}{l}\text { It would help job stress } \\
\text { researchers to make the } \\
\text { appropriate selection of } \\
\text { conferences, universities, and } \\
\text { journals to publish their } \\
\text { research work. It may affect } \\
\text { the citations of their paper in } \\
\text { the future }\end{array}$ \\
\hline $\begin{array}{l}\text { Which are the } \\
\text { leading } \\
\text { countries in the } \\
\text { publication of } \\
\text { job stress } \\
\text { papers? }\end{array}$ & $\begin{array}{l}\text { It would help to understand } \\
\text { the researchers and } \\
\text { practitioners that which } \\
\text { country is consternating more } \\
\text { on job stress. This will provide } \\
\text { them an opportunity to } \\
\text { contribute their research work } \\
\text { in that country for future } \\
\text { publications. }\end{array}$ \\
\hline $\begin{array}{l}\text { What is the } \\
\text { keyword and } \\
\text { citation } \\
\text { network of job } \\
\text { stress? }\end{array}$ & $\begin{array}{l}\text { It will be an easy searching } \\
\text { method for future researchers. }\end{array}$ \\
\hline
\end{tabular}

Source: Authors' Calculation 


\section{Data extraction}

For data extraction, it is very important to choose an appropriate search engine. Scopus is selected for this purpose. This selection was done because 1) Scopus is Elsevier's citation database and it is considered as a prominent index. 2) It publishes peer-reviewed highquality work. 3) Scopus measures quality for each title in four types i.e. h-index, Cite Score, SCI Imago Journal Rank (SJR), and Source Normalized Impact per Paper (SNIP). 4) Total 1490 research papers published in the field of job stress in Scopus indexes. The present research study was selected between 2010 to 2020 span of time. This search was done on 28 August 2020. A total of 851 research papers were published in this period. This search string was based on Scopus to search annual trends, authors, top journals, subject area, document type, affiliations, and top countries.

\section{RESULTS}

In this section bibliometric analysis of the Scopus database is presented. The analysis is carried out in such a way that it will answer all the formatted research questions.

\section{Distribution of Annual Trend}

The job stress was analyzed with bibliometric tools in the present research work. These trends show that job stress is much prevalent in working life these days. Every individual has a different perception that shapes his experience with stress (Webster, 2014). It is estimated that $74 \%$ of people were suffering from stress and they were unable to cope up with stress (Mental health Foundation, 2018). For employees everywhere, the work situation is like an emotional roller coaster that results in increased fear, uncertainty, and higher levels of stress (Ahmad, Parveen, \& Ahmad, 2012). Among them, 851 research papers were published from 2010 to 2020 . From the below fig. 1, it is clear that there was a decreasing trend from 2010 to 2012 by 69, 64, and 58 publications in job stress. From 2013, there was growth in publication, reaching a peak in 2016 (100 articles). In 2017, a sudden decrease was noted with 59 articles. Again a rise was found in 2018 and 2019 with 97 and 98 articles respectively. But in 2020 a fall was found with a total of 76 publications.

\section{Distribution of Authors}

The list of authors, who published at least 5 Number of Papers publications, is presented in fig.2, with a total of 12 such authors. At the top position in this list was Lambert, E.G., who published 15 of the top papers, followed by Tsutsumi (9 articles), Deng, J., Inoue, A., and Yang, T. (7 articles). Meanwhile, Hogan, N.L., and Kawakami, N published 6 articles. Guo, L, Kawada, T., Shimazu, A., Xu, W., and Zhao, Y. each contributed to job stress literature with 5 articles.

\section{Distribution of Top journals}

It is observed that a total of 81 journals published articles on job stress. In this study top, 9 journals are reported, having 8 or more publications. As fig. 3 shows, the maximum number of publications was published in the International Journal Of Environmental Research And Public Health (16), Iran Occupational Health(14), Work(13), Journal Of Occupational Health(12), Industrial Health(11), Advances In Environmental Biology(9), Annals Of Occupational And Environmental Medicine(8), Information Japan(8), Journal Of Occupational and Environmental Medicine(8) journals.

\subsection{Distribution of articles published by subject area}

Research areas Fig. 4 shows the top position research areas of job stress with the maximum number of publications. Medicine is ranked one with 371 publications. Social Sciences are at the second level, and Business Management and Accounting are at rank three with 177 and 149 publications respectively. Then, the top research areas were Psychology (108), Engineering (82), Nursing (76), Computer Science (51), Environmental Science (49), Economics, Econometrics and Finance (36), Biochemistry, Genetics and Molecular Biology (32), Agriculture and Biological Sciences (26), Arts and Humanities(25), Mathematics (17), Multidisciplinary (17), Decision Sciences (16), Pharmacology, Toxicology and Pharmaceutics (14), Chemical Engineering (12), Energy (10), Health Professions (8), Physics and Astronomy (8), Neuroscience (7), Earth and Planetary Sciences (5), Material Science (5), Dentistry (2) and Immunology and Microbiology (1).

\section{Distribution of document type}

In total 851 publications met the selection criteria in the document type. A total of 13 types were found in these 851 documents. The most frequent publication type is an article 
(737), accounting for $86.6 \%$ of total publications. Conference paper (39) is at second position with a proportion of $4.5 \%$. Other document type consisting book chapter (31), review (20), Letter (7), editorial (5), note
(4), book (2), short survey (2), data paper (1), Erratum (1), Retracted (1) and Undefined (1). Fig. 5 shows the numbers of various document types.

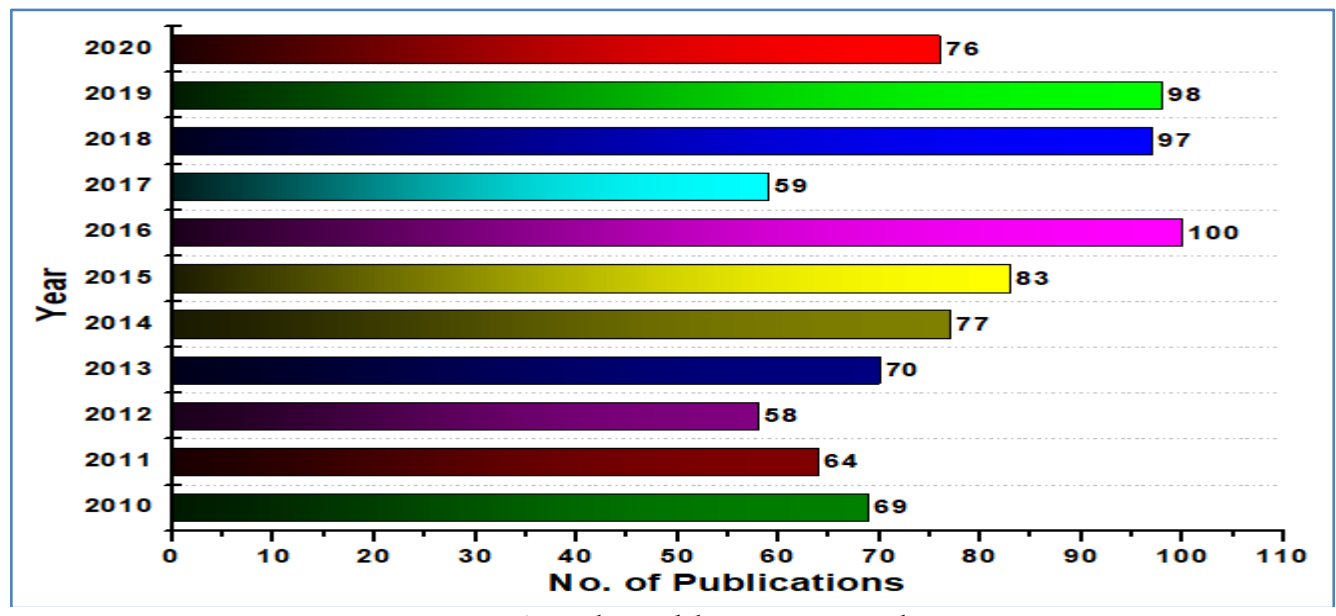

Source: Authors' Calculation

Fig.1. Yearly Publication Trend

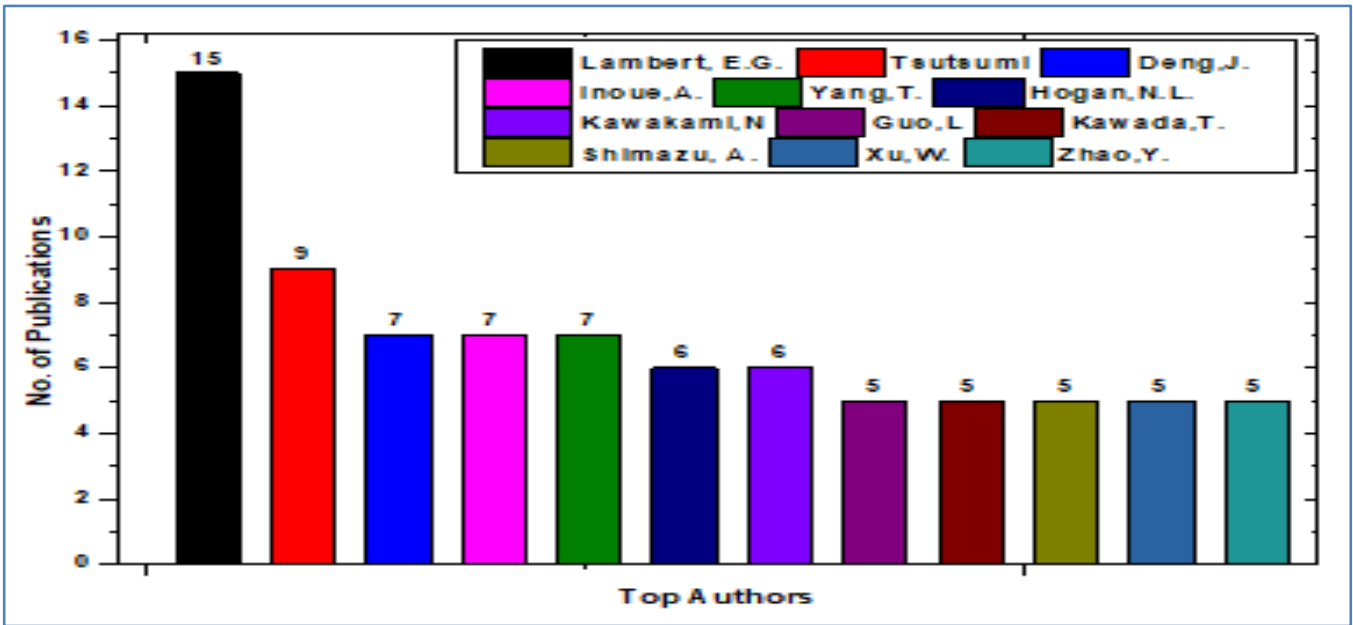

Fig. 2: Author's contribution

Source: Authors' Calculation

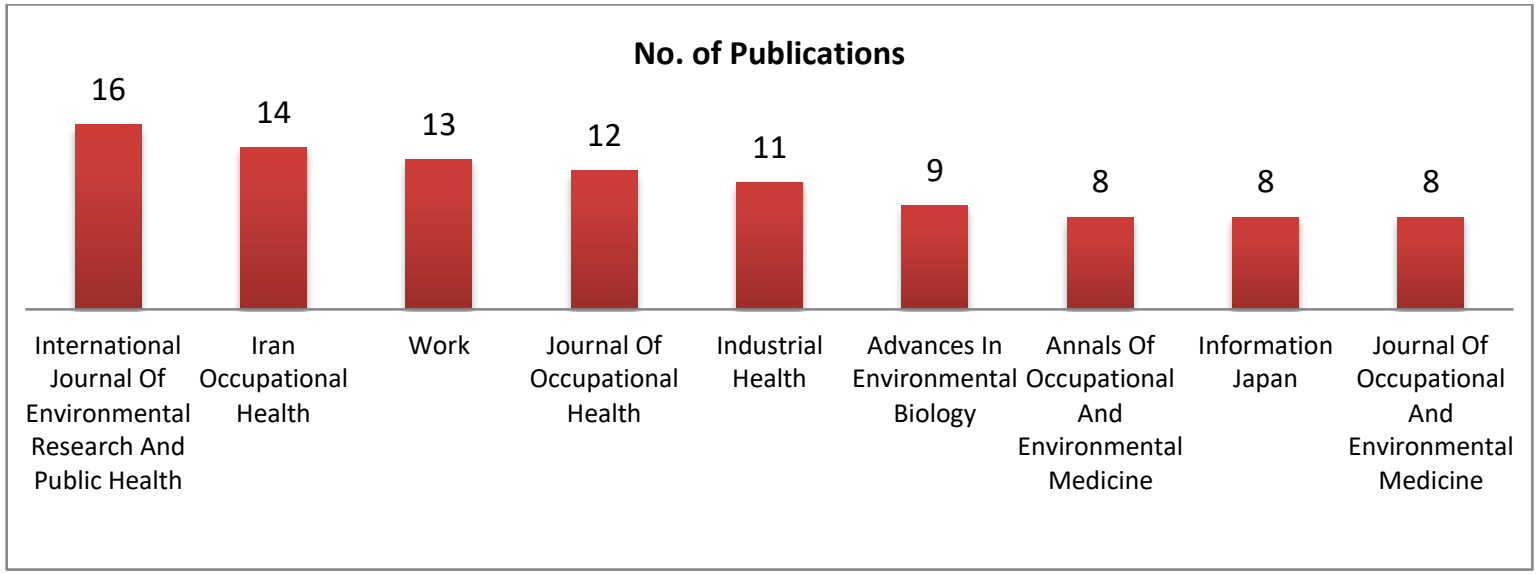

Fig.3. Journals having maximum publications

Source: Authors' Calculation 


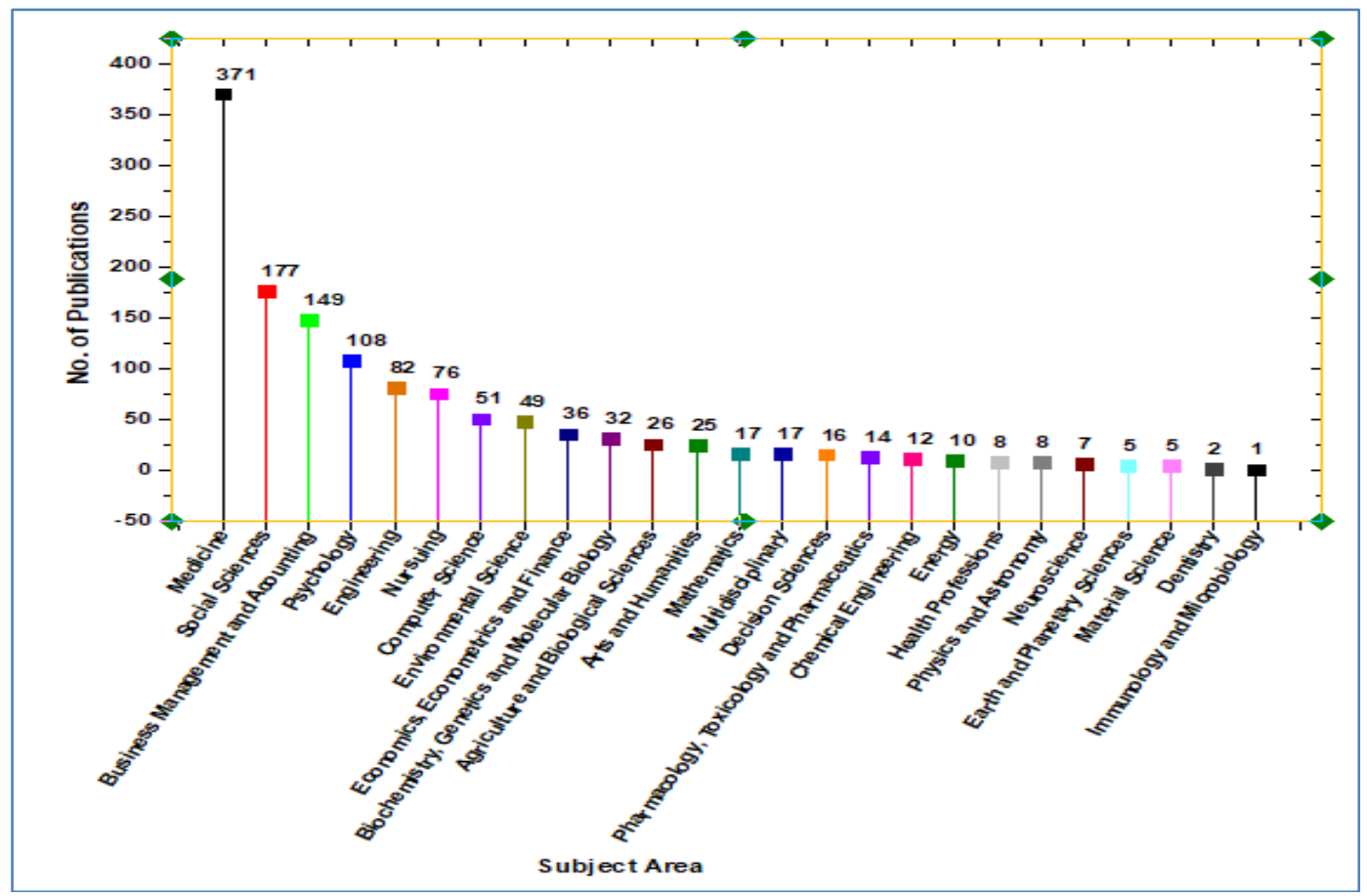

Fig.4. publications based on area

Source: Authors' Calculation

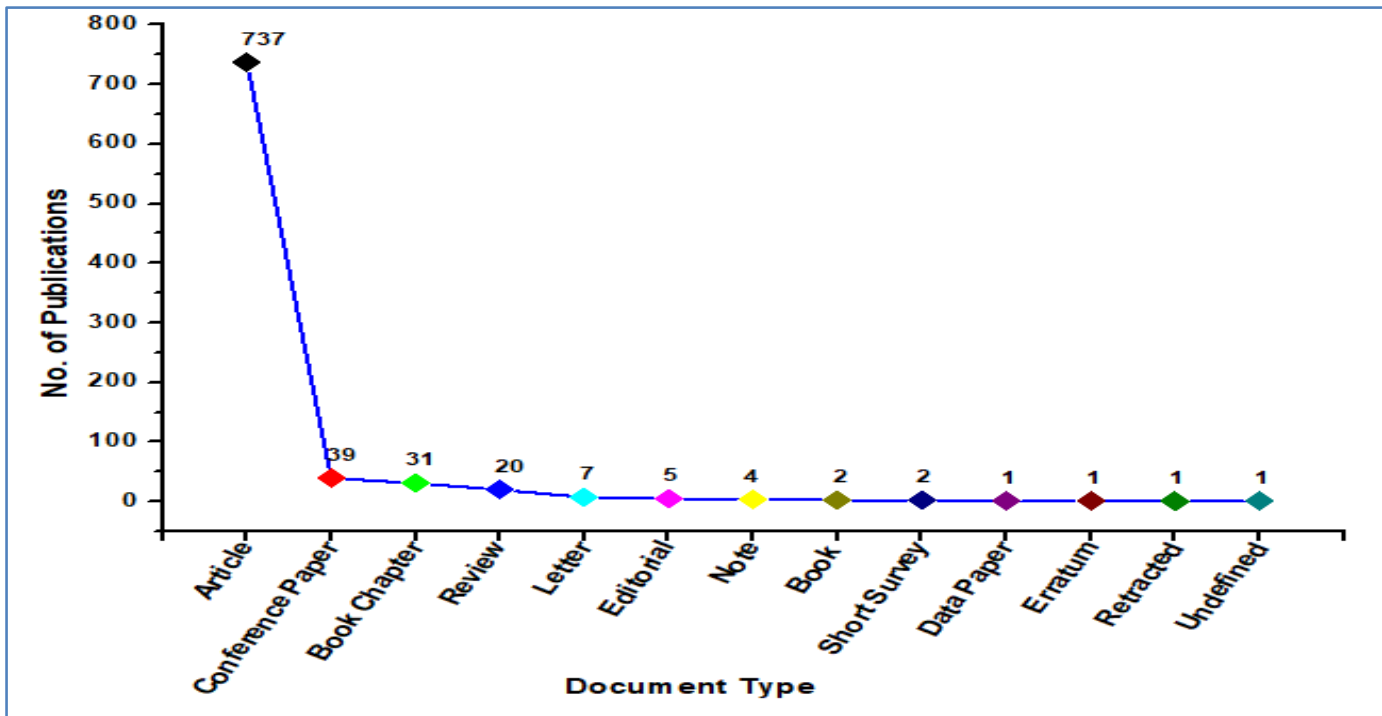

Fig.5. Types of publication

Source: Authors' Calculation

The Distribution of different Affiliations

Islamic Azad University has the maximum number of publications with 13 publications. The University of California, Los Angeles is in the second position with 11 publications followed by the University of Occupational and Environmental Health(10), University of Mississippi(10), Yonsei University (9), Shiraz University of Medical Sciences(9), Kitasato University School of Medicine(8), Wayne State University(8) as seen in fig. 6 .
Distribution of publications among countries In this section, the lists of countries, having the maximum number of publications are presented. Fig. 7 shows that the United States published the maximum number of papers i.e., 140 papers followed by $\mathrm{h}$ Korea with a count of 121 publications and then followed by Iran(102) China(73), Japan(51), India(49), Taiwan(43), Malaysia(29), Canada(28), United Kingdom(28), Germany(25), Australia(21), Pakistan(21) and Turkey(20). 


\section{Distribution of Keyword analysis}

Total 1717 keywords are extracted, but there were 80 keywords at the minimum number of occurrences of 5. The final network is developed and finally, 62 keywords are selected for further analysis. The selected keywords are classified into 10 clusters with different colors as shown in fig.8. Cluster one consists maximum of 11 items.

It has been observed that most of the researchers have been found the keyword for job stress in effort-reward imbalance followed by gender and job strain.

\section{Distribution of citations}

In the citation of countries, 24 meet the threshold among 62 countries. Minimum 8 citations of a country counted in the study. The United Kingdom has maximum citations followed by the United States and South Korea. Fig. 9shows the citations of different countries for job stress.

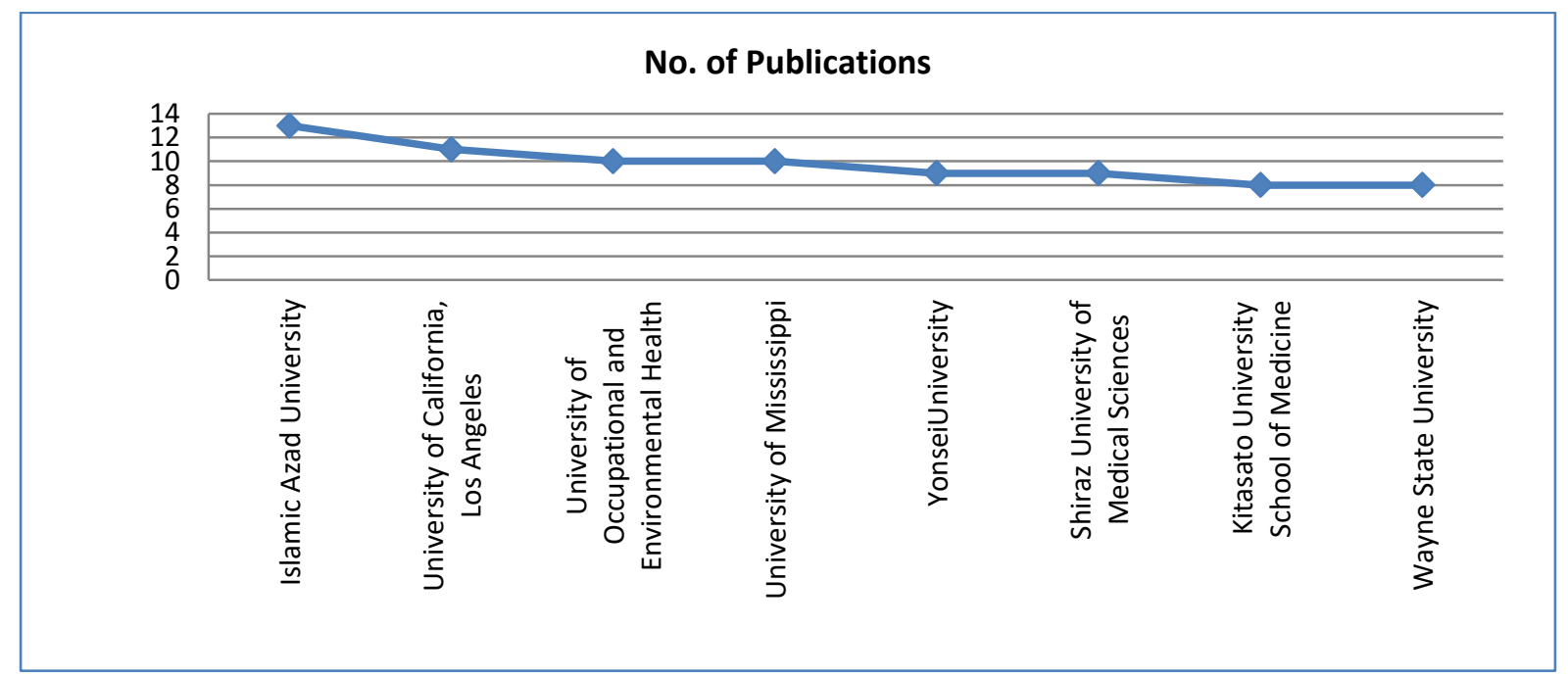

Source: Authors' Calculation

Fig.6.Organizations with the highest Publications

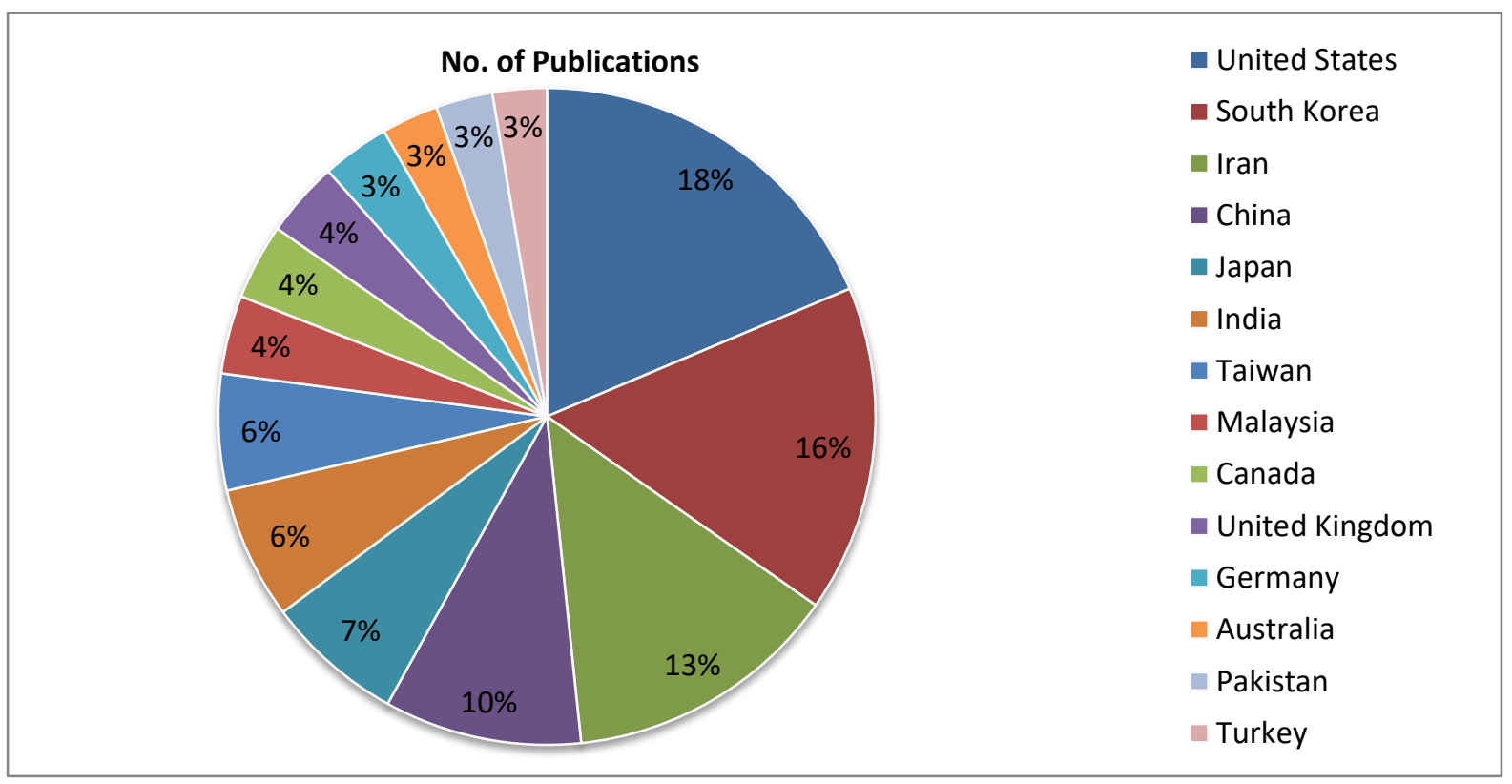

Source: Authors' Calculation

Fig.7. Countries with top Publications 


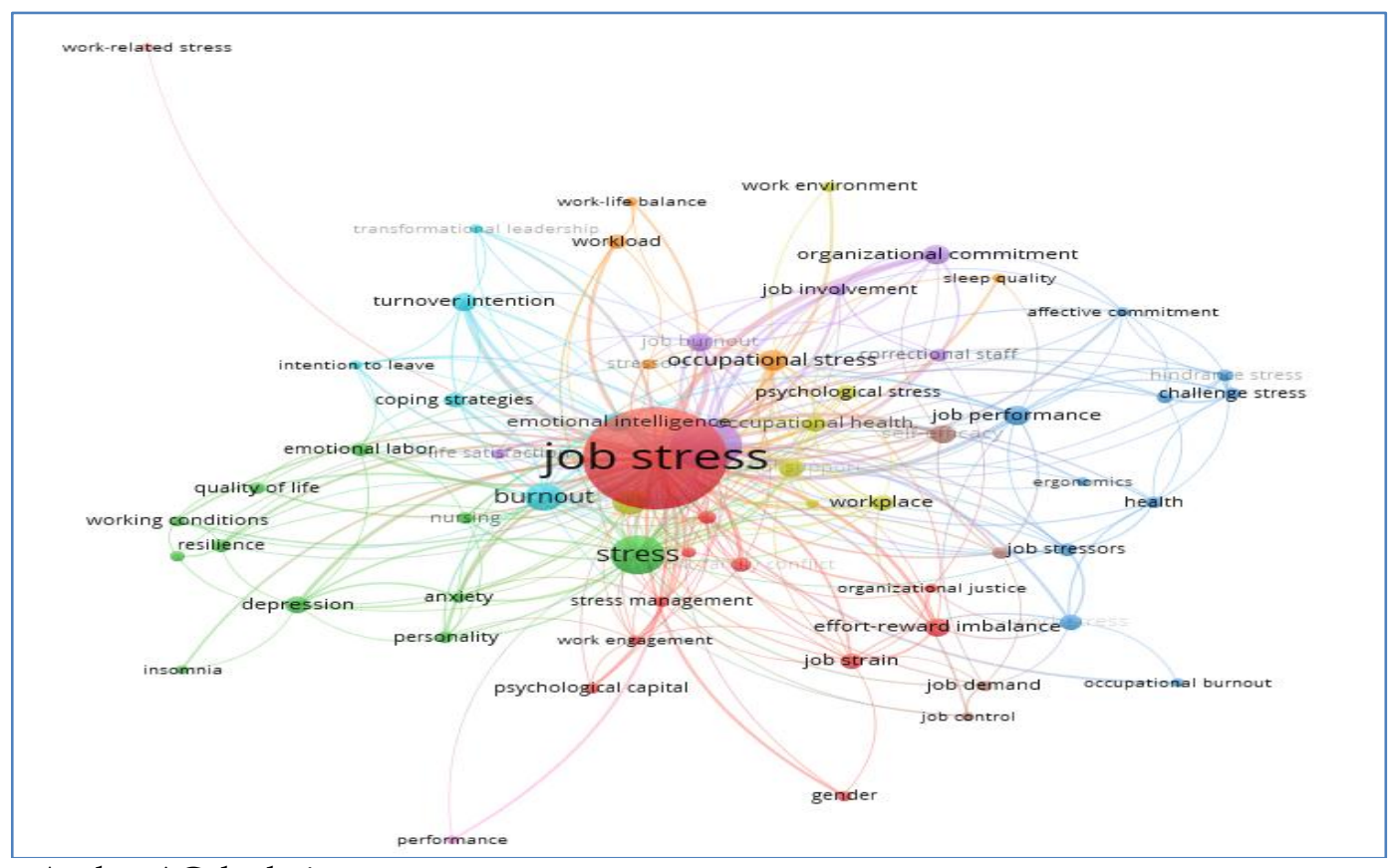

Source: Authors' Calculation

Fig.8. Keyword Analysis

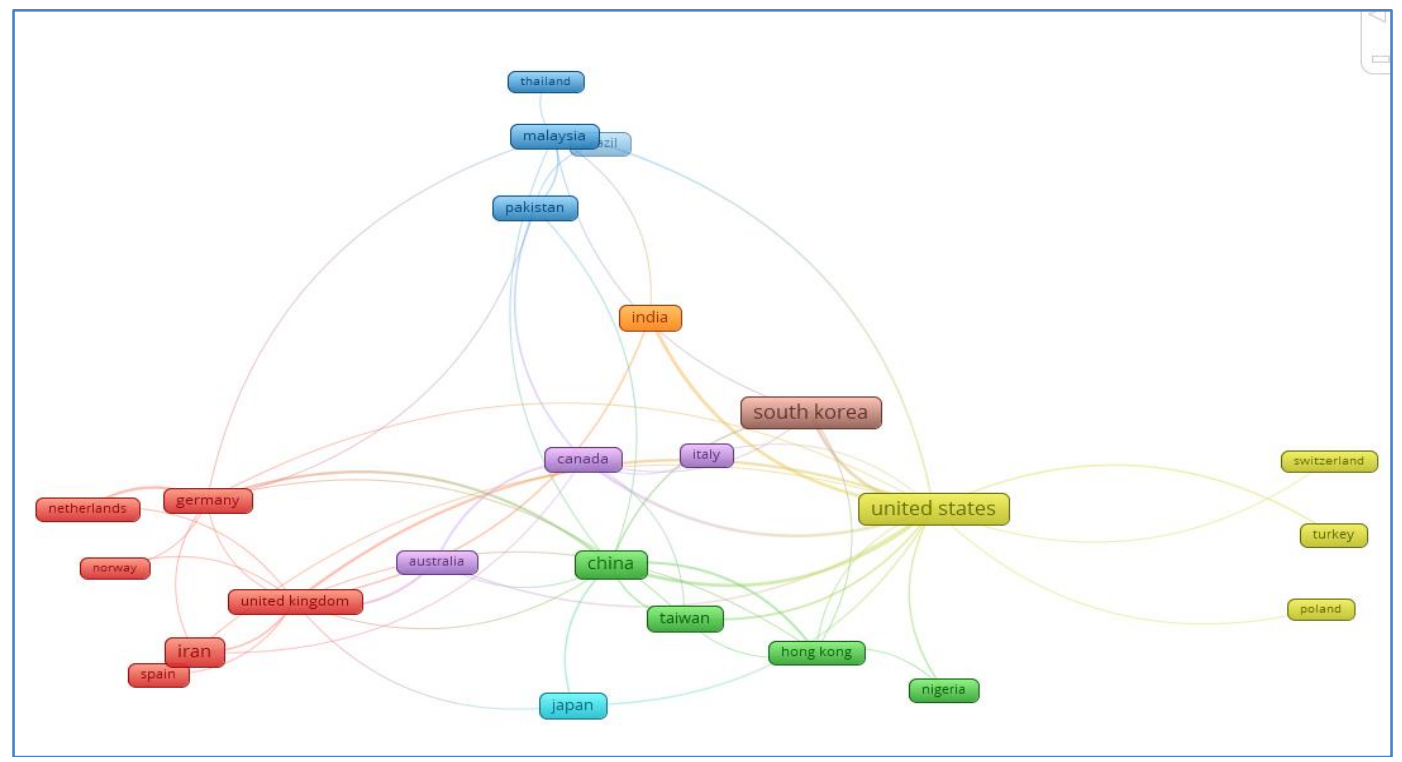

Source: Authors' Calculation

Fig.9. Citation in Countries

\section{DISCUSSION}

In the discussion section, answers to research questions formulated in the methodology section are discussed.

RQ1: What is the annual Trend of job stress publications?

The publication trend of job stress papers is presented in Fig. 1, which provides some important information. Fig. 1 presents the annual number of publications of job stress papers with increasing and decreasing trends. There was a decreasing trend from 2010 to
2012 in the publications of job stress. From 2013, there was a rapid increase in publication, reaching a peak in 2016 with 100 articles. In 2017, a sudden decrease was noted with 59 articles. Again a rise was found in 2018 and 2019. But in 2020 publications were dropped at 76 only.

RQ2: Which author and journal contributed more to job stress based research?

In this section, the contribution of different authors and journals in job stress papers are examined. Fig. 2 presents that Lambert, E.G. 
published a maximum of 15 papers on job stress, followed by Tsutsumi, Deng, J., Inoue, A., and Yang, T. Fig. 3 represents the Maximum number of publications in journals. International Journal of Environmental Research and Public Health journal was at the top in publications of papers on job stress followed by Iran Occupational Health, Work and Journal of Occupational Health.

RQ3: Which area and document type published more research work on job stress?

Fig. 4 shows that Medicine is ranked one with 371 publications in research areas for job stress. Social Sciences is the second level, and Business Management and Accounting are at rank three. Then, the top research areas of job stress publications are Psychology, Engineering, Nursing, and Computer Science. Total 13 types of documents found in job stress publications as shown in fig. 5 . The most frequent publication type is articles with $86.6 \%$ of total publications. The conference paper is in the second position. Other document types consisting book chapter, review, Letter, editorial, note, book, short survey, data paper, Erratum, Retracted, and Undefined.

RQ4: What is the topmost publication Affiliations for Job stress papers?

In this section, the topmost publication Affiliations in job stress based on Scopus database are discussed. Islamic Azad University has the most publications on job stress. The University of California and Los Angeles is in the second position followed by the University of Occupational and Environmental Health and the University of Mississippi.

RQ5: Which are the leading countries in the publication of job stress papers?

Fig. 5 shows that the United States is at the top position for publication of a maximum number of papers with140 papers followed by South Korea, Iran, China, and Japan.

RQ6: What are the keyword network and citations of job stress?

In the final network, 62 keywords are selected for analysis. The selected keywords are classified into 10 clusters with different colors as shown in fig.8. Cluster one consists maximum of 11 items. Effort-reward imbalance followed by gender and job strain was found as the most occurred keywords in job stress. In the citation, 24 countries meet the thresholds, having citations more than 8 . It was found that the United Kingdom has the highest citations of job stress.

\section{Theoretical Implications}

Overall, the current study has made the following type of contributions:

- This research reports that it is the first attempt in Scopus literature to carry out a bibliometric analysis in job stress.

- Secondly, the results extracted from the analysis of the bibliometric study will introduce some significant implications for future researchers by giving them a new direction for their further investigations in research.

\section{Limitations and future scope of the study.}

This research explores various and related possible future research in job stress which may include publications on highly cited research papers including technical aspects using different types of literature database like WoS (Web of Sciences) and other internet databases to check the similarity of this study

\section{CONCLUSION}

In this research, a bibliometric analysis of job stress is presented. 851 papers were retrieved from the Scopus database covering the 2010 to 2020 time span. It is found from the analysis that the interest of researchers in job stress was at a peak in 2016. After 2016, there was a random increase and decrease in publications on job stress. The top research area associated with job stress includes medicine, Social Sciences, and Business Management \& accounting. Lambert, E.G. contributed the most in job stress publications. Most of the publications found on job stress are in the form of articles. Maximum research on job stress published under Islamic Azad University's affiliation.

\section{REFERENCES}

Ahmad, H. K., Parveen, S., \& Ahmad, U. (2012). A study on seasonal variations of benthic community and biodiversity indices about environmental variables in disturbed ponds. Agris On-Line Papers in 
Economics and Informatics, 2(4), 2139-2144. https://doi.org/10.6088/ijes.0020203009 7

Arevalo, J. P. M., \& Balodi, A. B. (2019). The impact of pro-social and violent video games on helping attitude a comparative study. Journal of Content, Community and Communication, 9(2019), 1-5. https:// doi.org/10.31620/JCCC.06.19/02

Fong, Y. L. (2019). Gender representation and framing of Malaysian women: A study of feature articles in a female magazine. Journal of Content, Community and Communication, 10(5), 29-38. https:// doi.org/10.31620/JCCC.12.19/04

Jaswal, V., \& Chand, P. (2018). Development of survey instrument for software professionals' job stress: a factor and confirmatory factor analysis approach. Int. J. Business Innovation and Research, 17(3), 394-416.

Kundaragi, P. B. (2015). Work Stress of Employee: A literature review. International Journal of Advance Research And Innovative Ideas, 1(3), 18-23.

Li, L., Ai, H., Gao, L., Zhou, H., Liu, X., Zhang, Z., ... Fan, L. (2017). Moderating effects of coping on work stress and job performance for nurses in tertiary hospitals: A cross-sectional survey in China. BMC Health Services Research, 17(1), 1-8. https://doi.org/10.1186/ s12913-017-2348-3

Mental health Foundation. (2018). Stress: Are we coping?

Miglani, N., \& Brar, P. (2017). Mapping the Work-home conflict of Indian Fashion \& lifestyle journalists: A study of Punjab, Haryana and Himachal Pradesh Bureaus. Journal of Content, Community and Communication, 5(1989), 7-14.

National Statistics. (2018). Work-related stress, depression, or anxiety in Great Britain. Health and Safety Executive. Retrieved from http://www.hse.gov.uk/statistics/ causdis/stress/index.htm

Ramanathan, N. (2014). Job stress - An empirical investigation of women employees working in the Indian Banking sector. P.hd Thesis. Alagappa University.
Ray, T. K., Kenigsberg, T. A., \& Pana-Cryan, R. (2017). Employment arrangement, job stress, and health-related quality of life. Safety Science, 100, 46-56. https:// doi.org/10.1016/j.ssci.2017.05.003

Seňová, A., \& Antošová, M. (2014). Work Stress as a Worldwide Problem in Present Time. Procedia - Social and Behavioral Sciences, 109(February), 312316. https://doi.org/10.1016/j.sbspro. 2013.12.463

Shiva, A., Narula, S., \& Shahi, S. K. (2020). What drives retail investors' investment decisions? Evidence from no mobile phone phobia (Nomophobia) and investor fear of missing out (I-FoMo). Journal of Content, Community and Communication, 10(6), 2-20. https:// doi.org/10.31620/JCCC.06.20/02

Sidhu, A. K., Singh, H., Virdi, S. S., \& Kumar, R. (2019). Identification of sources of job stress: A study among officers and supervisors. International Journal of Indian Culture and Business Management, 19(2), 147-167. https://doi.org/10.1504/ijicbm. 2019.10019640

Sidhu, A. K., Singh, H., Virdi, S. S., \& Kumar, R. (2020). Job stress and its impact on the health of employees: a study among officers and supervisors. Journal of Management Development, 39(2), 125-144. https://doi.org/10.1108/JMD-01-20190004

Tripathi, S. (2015). Need for Psychological Empowerment of Women in India. Journal of Content, Community $\mathcal{E}$ Communication, 1, 35-40.

Webster, J. H. (2014). Perceived stress among police officers: An integrative model of stress and coping. Policing: An International Journal of Police Strategies $\mathcal{E}$ Management, 37(4), 839-857. https:// doi.org/10.1108/PIJPSM-06-2014-0064

Yeasmin, N., Ara, A., Khan, S. N., \& Hossain, M. . M. (2015). Workers occupational stress problem in selected industry Nilufa Yeasmin. International Journal of Indian Culture and Business Management, 10(3), 318-334. 